\title{
Bioluminescent Methods for Determining Metabolites in Micro-Samples of Pig Plasma ${ }^{1}$ )
}

\author{
Melinda J. Thompson, Peter G. Arthur and Peter E. Hartmann
}

Department of Biochemistry, The University of Western Australia, Nedlands, Australia

Summary: A highly sensitive and simplified method for the luminometric determination of plasma metabolites has been developed. Furthermore, the technique has been automated for the Dynatech ML2250 Microtiter Plate Luminometer and can be applied to the measurement of any plasma metabolite which may be coupled to a reaction involving the reduction of $\mathrm{NAD}^{+}$. Assays are described for lactose/galactose, $\beta$-hydroxybutyrate and $D$-lactate, and have been validated with plasma samples. The assays require $1-2 \mu l$ of plasma, and are capable of detecting concentrations below $5 \mu \mathrm{mol} / \mathrm{l}$. Since luminometry is based on the kinetics of the luciferase/oxidoreductase enzyme system, components of complex biological samples may interfere with the rate of the reaction; necessitating the use of internal standards for individual samples. However, the need for internal standards to account for sample to sample variation in the luminescent response, has been eliminated with the present technique.

\section{Introduction}

Luminometry involving bacterial luciferase ${ }^{2}$ ) is based on the production of light during a two stage reaction catalyzed by luciferase and NAD(P)H:FMN oxidoreductase $^{2}$ ), and requiring reduced nicotinamide adenine dinucleotide (NADH), flavin mononucleotide (FMN), a long chain aldehyde and molecular oxygen. When all other substrates are present in excess, the rate of light production is dependent upon the concentration of NADH. Thus, pre-existing assays involving the production of $\mathrm{NAD}(\mathrm{P}) \mathrm{H}$ may be coupled to a luminescent reaction, providing greater sensitivity than can be obtained in either a spectrophotometer or fluorometer $(1-2)$.

Recent advances in bioluminescent assays (1-3) have decreased the volume of sample required for the analysis of multiple metabolites. This allows frequent blood sampling from small animals without a significant reduction in blood volume. Furthermore, it is often advantageous to collect finger-prick blood samples from humans.

\footnotetext{
1) Funding Organisation:

Pig Research and Development Corporation of Australia

2) Enzymes:

Galactose dehydrogenase:

$D$-Galactose : NAD ${ }^{+}$1-oxidoreductase (EC 1.1.1.48); $\beta$-Galactosidase:

$\beta-D$-Galactoside galactohydrolase (EC 3.2.1.23);

Hydroxybutyrate dehydrogenase:

[R]-3-Hydroxybutanoate : $\mathrm{NAD}^{+}$oxidoreductase

(EC 1.1.1.30);

$D$-Lactate dehydrogenase:

[R]-Lactate : $\mathrm{NAD}^{+}$oxidoreductase (EC 1.1.1.28);

Luciferase:

Alkanal : reduced-FMN-oxygen oxidoreductase (EC 1.14.13.3);

Oxidoreductase:

$\mathrm{NAD}(\mathrm{P}) \mathrm{H}:$ FMN oxidoreductase (EC 1.6.8.1).
}

However, the usefulness of bioluminescence as an analytical tool has been hindered by the expense and limited stability of the reagent (1). Furthermore, previously described bioluminescent assays have presented measurements either from standards and not biological samples, or have required internal standards to account for the interference from the samples $(2,4,5)$.

We have developed a semi-automatic procedure which allows the rapid measurement of any plasma metabolite which can be coupled to a NADH-producing reaction. In addition to decreasing the cost of the assays, and increasing the stability of the reagents, the sensitivity of the technique described here has allowed large dilution of the sample, thus removing sample-specific inhibition of the kinetic, bioluminescent reaction.

The assays described here were chosen for their possible clinical significance. Plasma lactose may provide an indication of gastrointestinal disorders associated with increased gut permeability (6), while increases in the plasma concentration of $\boldsymbol{\beta}$-hydroxybutyrate and $D$-lactate are associated with ketosis and acidosis, respectively.

\section{Materials and Methods \\ Materials}

All reagents were prepared from analytical grade chemicals and were dissolved in de-ionized water.

Bioluminescent reagent

The first step in the assays was the metabolite-specific reaction resulting in the production of NADH; the reagents for which are described below. However, the measurement of the NADH through the bioluminescent reaction was common to all the assays and the 
reagent was prepared as described by Arthur \& Hochachka (3) with the following modifications. The reagent contained potassium phosphate $(100 \mathrm{mmol} / \mathrm{l})$, bovine serum albumin (essentially fatty acid free; $16 \mathrm{~g} / \mathrm{l}$ ), EDTA (disodium salt; $4 \mathrm{mmol} / \mathrm{l}$ ), FMN $(8 \mu \mathrm{mol} / 1)$, tetradecanal (Aldrich Chemical Co., NY: $1 \mathrm{~g} / 1)$ and luciferase $^{2}$ ) (Sigma Chemical Co.: EC 1.14.14.3: protein $0.2 \mathrm{~g} / \mathrm{l}$ ) in tris[hydroxymethyl]methyl-2-aminoethanesulphonic acid (TES) buffer $(300 \mathrm{mmol} / \mathrm{l}, \mathrm{pH} 6.8)$ and was aliquoted and frozen at $-80^{\circ} \mathrm{C}$. The reagent was stable for at least four months if stored at $-80^{\circ} \mathrm{C}$ and protected from light. The addition of a second enzyme was not required since the luciferase preparation was contaminated with oxidoreductase. The light response obtained was similar to previous experiments $(1,3)$ which used pure enzyme preparations of luciferase (6 mg/l final reaction volume) and oxidoreductase (33 U/1 final reaction volume), however, the impure Sigma preparation represented a significant reduction in cost.

\section{Reagents for metabolite assays}

The $\beta$-hydroxybutyrate assay was based on the conversion of $\beta$ hydroxybutyrate to acetoacetate by hydroxybutyrate dehydrogenase $^{2}$ ) (Boehringer Mannheim, North Ryde, Australia: EC 1.1.1.30), with the co-production of NADH. The assay was adapted from an existing spectrophotometric iron-chelate assay (7). Since the equilibrium for $\beta$-hydroxybutyrate dehydrogenase is unfavourable for acetoacetate formation (8), the reaction was driven with hydrazine. Reagent A for $\beta$-hydroxybutyrate, containing hydrazine sulphate $(50 \mu \mathrm{mol} / 1), \mathrm{NAD}^{+}(250 \mu \mathrm{mol} / 1)$, and hydroxybutyrate dehydrogenase $(40 \mathrm{U} / \mathrm{l})$ in TES buffer $(0.1 \mathrm{~mol} / \mathrm{l}, \mathrm{pH} 8.4)$, was prepared fresh for each sample set. The ammonium sulphate suspension of hydroxybutyrate dehydrogenase was unsuitable for long term storage of the enzyme. However, resuspension in a buffer containing calcium chloride $(1 \mathrm{mmol} / \mathrm{l})$ in potassium phosphate $(10$ $\mathrm{mmol} / \mathrm{l} ; \mathrm{pH} 7$ ) allowed storage of the enzyme at $-20^{\circ} \mathrm{C}(9)$, and decreased the background readings.

The $D$-lactate assay was a modification of an existing fluorometric assay (10) involving conversion by $D$-lactate dehydrogenase ${ }^{2}$ ) (Sigma Chemical Col, Missouri, USA: EC 1.1.1.28). Reagent A for $D$-lactate was prepared fresh and contained hydrazine sulphate $(5 \mathrm{mmol} / \mathrm{l})$, ascorbic acid $(2 \mathrm{mmol} / \mathrm{l}), \mathrm{NAD}^{+}(2 \mathrm{mmol} / \mathrm{l})$ and $D$ lactate dehydrogenase $(51 \mathrm{kU} / \mathrm{l})$ in glycine buffer $(1 \mathrm{~mol} / 1, \mathrm{pH} 9)$.

A spectrophotometric assay for the determination of galactose (11) was modified for the measurement of lactose on the luminometer. Lactose was hydrolyzed by $\beta$-galactosidase ${ }^{2}$ ) (Boehringer Mannheim: EC 3.2.1.23) and the galactose moiety reacted in the presence of galactose dehydrogenase ${ }^{2}$ ) (Boehringer Mannheim: EC 1.1.1.48). The reagents for the measurement of lactose could be prepared in advance, were stable, and showed no increase in background readings, if stored on ice for 24 hours. Lactose reagent $A$ (for hydrolysis of lactose) contained $\mathrm{MgCl}_{2}(1.9 \mathrm{mmol} / \mathrm{l})$ and $\beta$ galactosidase $(3 \mathrm{kU} / \mathrm{l})$ in potassium phosphate buffer $(85 \mathrm{mmol} / \mathrm{l}$, $\mathrm{pH}$ 8), while reagent $\mathrm{B}$ (for oxidation of galactose) contained $\mathrm{MgCl}_{2}(1.9 \mathrm{mmol} / \mathrm{l}), \mathrm{NAD}^{+}(2.9 \mathrm{mmol} / \mathrm{l})$ and galactose dehydrogenase $(1.2 \mathrm{kU} / \mathrm{l})$ in potassium phosphate buffer $(85 \mathrm{mmol} / 1, \mathrm{pH})$.

\section{Apparatus}

Working standards were checked on a Titertek Multiskan ${ }^{\circledR} \mathrm{MCC} /$ 340 plate reader (Flow Laboratories, McLean, VA, USA). Otherwise a Dynatech ML2250 Microtiter Plate Luminometer (Dynex, Chantilly, VA, USA) was used.

\section{Plasma samples}

Blood samples $(60 \mu \mathrm{l})$ were taken from the ear vein of 11 Landrace and Large White (pure and cross-breed) piglets according to the method of Holmes et al. (11). Plasma was separated by centrifugation at $3000 \mathrm{~g}$ for 5 minutes, deproteinized with perchloric acid $(0.6 \mathrm{~mol} / \mathrm{l})$ and neutralized according to the method of Arthur et al. (1), and buffered $(0.1 \mathrm{~mol} / \mathrm{l} ; \mathrm{pH} \approx 7)$ with either glycine ( $D$ lactate assay) or phosphate ( $\beta$-hydroxybutyrate and lactose) before being stored at $-20^{\circ} \mathrm{C}$. Blanks consisting of de-ionized water, standards, and plasma samples used as quality controls, were also deproteinized with each set of samples.

\section{Procedure}

Deproteinized samples were planted onto 96-well V-bottomed plates (Flow Laboratories, McLean, VA, USA) and reagent added. Assay conditions for the metabolite-specific reactions are outlined in table 1. All samples were measured in duplicate. Two sets of sample duplicates were used in the lactose assay; one set was incubated with reagent $A$ minus the $\beta$-galactosidase to account for the concentration of free galactose in the plasma.

The final reactions were stopped with the addition of $150 \mu \mathrm{l}$ of sodium hydroxide $(10 \mathrm{mmol} / \mathrm{l})$. Aliquots $(5 \mu \mathrm{l})$ from each well were transferred to an opaque, white Microlite ${ }^{\circledR}$ 96-well roundbottomed plate, further diluted with $10 \mathrm{mmol} / \mathrm{l}$ sodium hydroxide $(40 \mu \mathrm{l})$ and then $15 \mu \mathrm{l}$ of bioluminescent reagent was injected. The luminometer was programmed for a 5 second delay after addition of the bioluminescent reagent, followed by a 1 second read period. The peak and mean light response over the latter period was calculated. In all cases, the mean light response was used. Samples were repeated if duplicates differed by more than $10 \%$.

\section{Results}

\section{Bioluminescent assay}

The 5 second delay period after injection of the bioluminescent reagent was sufficient to ensure that the kinetic reaction had reached a plateau before the response was read for a further 1 second. The reaction was not limited by substrate supply over this period (fig. 1). The detection limit of the bioluminescent assay, defined as the lowest concentration of NADH in the reaction well that was significantly different from the mean $(n=4)$ light response of the blanks (at 99\% confidence) was 0.5 $\mathrm{nmol} / 1$, and the response was linear $\left(\mathrm{r}^{2}=0.999\right)$ to 2.5 $\mu \mathrm{mol} / \mathrm{l}$ of NADH (fig. 2).

\section{Standard curves}

The reactions were checked to ensure that they had reached completion within the incubation time and that there was no drift reactions due to contaminating enzymes or metabolites. To check accuracy, the standards of $\beta$-hydroxybutyrate, $D$-lactate and lactose were reacted, and the change in absorbance at $340 \mathrm{~nm}$ checked against known concentrations of NADH. The light response to deproteinized standards increased linearly

Tab. 1 Details of metabolite assays

\begin{tabular}{llll}
\hline & \multicolumn{2}{l}{ Assay } & \\
\cline { 2 - 4 } & $\begin{array}{l}\text { Hydroxy- } \\
\text { butyrate }\end{array}$ & $D$-Lactate & Lactose \\
& 20 & 10 & 10 \\
Sample $(\mu 1)$ & 50 & 30 & 20 \\
Reagent A $(\mu 1)$ & 60 & 90 & 60 \\
Incubation time A (min) & 25 & 25 & 37 \\
Incubation temp. A $\left({ }^{\circ} \mathrm{C}\right)$ & & & 10 \\
Reagent B $(\mu 1)$ & & & 60 \\
Incubation time B (min) & & & 37 \\
Incubation temp. B $\left({ }^{\circ} \mathrm{C}\right)$ & & &
\end{tabular}


$\left(r^{2} \geq 0.998\right)$ with an increase in the concentration of the standards up to $1 \mathrm{mmol} / \mathrm{l}$.

\section{Recoveries, imprecision and detection limit}

The addition of three spikes of increasing concentration $(25,50$ and $100 \mu \mathrm{mol} / \mathrm{l})$ to aliquots of three different samples of piglet plasma showed complete recovery of the various metabolites (tab. 2). The metabolites were stable in plasma for at least 6 months if deproteinized and stored at $-20^{\circ} \mathrm{C}$. The enzyme $D$-lactate dehydrogenase was specific for $D$-lactate and did not react with the $L$-isomer of lactate, although the $L$-lactate salt (Boehringer Mannheim, Lot \# 11742634-43) was contaminated by the $D$-isomer (approximately 1\%). Further-

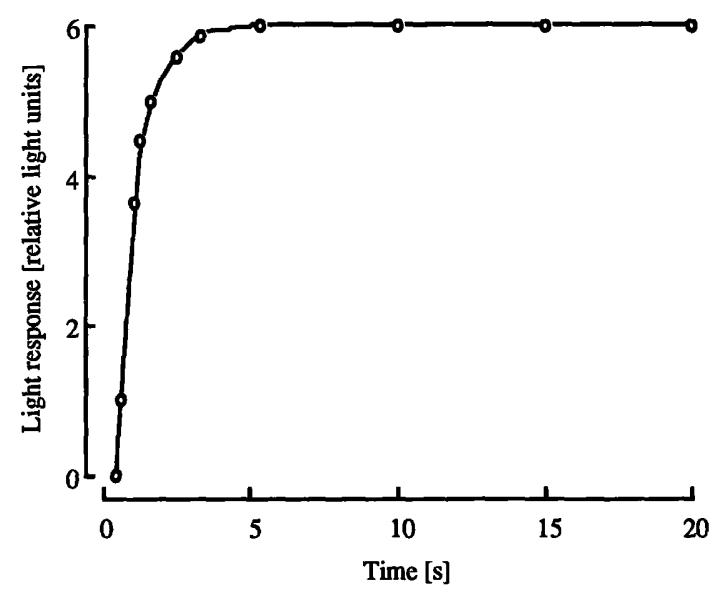

Fig. 1 The light response after injection of bioluminescent reagent $\left(t_{0}\right)$ into a well containing NADH. The reagent $(15 \mu l)$ was injected into a final volume of $60 \mu$ l containing approximately $2 \mu \mathrm{mol} / 1 \mathrm{NADH}$ in $7.5 \mathrm{mmol} / 1 \mathrm{NaOH}$.



Fig. 2 Standard curve for NADH. The concentration of NADH is given as the final concentration in the luminometer reaction well. The regression line for concentrations below $2 \mu \mathrm{mol} / 1$ (a) was $y=0.06+3.5 x\left(r^{2}=0.999\right)$. more, incubation in $0.6 \mathrm{~mol} / \mathrm{l}$ perchloric acid for several hours at room temperature did not result in the racemization of $L$-lactate into $D$-lactate.

The within-plate imprecision of the luminometer was evaluated by transferring aliquots of a NADH solution to each well of the luminometer plate. The light response $(R L U)$ was $0.674 \pm 0.023 \mathrm{RLU}(\mathrm{n}=96, \mathrm{C} . \mathrm{V} .=3.3 \%)$ for the plate if the temperature of the machine was set at $30^{\circ} \mathrm{C}$ and the plate was equilibrated for 5 minutes before being run. The reproducibility of the assays was checked by including a sample (quality control) of known concentration on all plates. The quality controls (mean $\pm \mathrm{SD})$ measured $133 \pm 8 \mu \mathrm{mol} / \mathrm{l}(\mathrm{CV}=6 \%$; $\mathrm{n}=9)$ for $D$-lactate, $59 \pm 3 \mu \mathrm{mol} / 1(\mathrm{CV}=5 \% ; \mathrm{n}=17)$ for lactose and $15 \pm 0.6 \mu \mathrm{mol} / 1(\mathrm{CV}=4 \% ; \mathrm{n}=7)$ for $\beta$-hydroxybutyrate (tab. 2).

The assays had a high sensitivity (tab. 2) although dilution of the sample at deproteinization resulted in a substantial decrease in sample sensitivity. Thus, the sample sensitivity was defined as the lowest concentration in the undiluted sample that was significantly different (at 99\% confidence) from the mean blank response.

\section{Interference studies}

Inhibition of the light response by the components of the metabolite-specific reagents was minimized by the high dilution of the initial reaction mixture prior to transfer to the Microlite ${ }^{\text {(3) }}$ plates. The effects of the various components on the light response are given in table 3 .

\section{Metabolite concentrations in piglet plasma}

The concentration of lactose in the peripheral plasma of the piglet peaked at $24 \mathrm{~h}$ after birth $(211 \pm 49 \mu \mathrm{mol} / \mathrm{l})$ and decreased thereafter (fig. 3). The concentration of $\beta$-hydroxybutytate in the plasma of the newborn piglets was less than $5 \mu \mathrm{mol} / \mathrm{l}$. The concentration increased during the first 3 hours to $15 \pm 4 \mu \mathrm{mol} / \mathrm{l}$ and remained relatively stable for the duration of the sampling period (12 $\pm 7 \mu \mathrm{mol} / \mathrm{l})$. The concentration of $D$-lactate in the peripheral plasma of the young piglet was low at birth ( $22 \pm 2 \mu \mathrm{mol} / \mathrm{l}$ ) but increased significantly by $72 \mathrm{~h}$, and continued to increase thereafter, reaching $423 \pm 79$ $\mu \mathrm{mol} / \mathrm{l}$ at $120 \mathrm{~h}$ (fig. 4).

\section{Discussion}

The technique described here is substantially simpler than previous luminometric techniques, and has eliminated the need for the inclusion of internal standards to account for variation in the kinetic response between samples and between standards and samples (2). Furthermore, this technique represents an improvement in sensitivity and a decrease in the cost of the biolumi- 
Tab. 2 Recovery of known concentrations of spikes added to samples of piglet plasma, the inter-assay variation, and the sample and assay sensitivity of the metabolite assays.

\begin{tabular}{|c|c|c|c|c|c|c|c|c|}
\hline & \multicolumn{2}{|c|}{ Recovery (\%) } & \multicolumn{2}{|c|}{ Inter-assay variation } & \multicolumn{4}{|l|}{ Sensitivity ${ }^{1}$} \\
\hline & \multirow[b]{2}{*}{ Mean $\pm \mathrm{SE}$} & \multirow[b]{2}{*}{$\mathrm{n}$} & \multirow[b]{2}{*}{$\%$} & \multirow[b]{2}{*}{$\mathrm{n}$} & \multicolumn{2}{|c|}{ Sample $^{a}(\mu \mathrm{mol} / 1)$} & \multicolumn{2}{|c|}{ Assayb $^{b}(\mathrm{nmol} / \mathrm{l})$} \\
\hline & & & & & Mean $\pm \mathrm{SE}$ & $\mathbf{n}$ & Mean $\pm \mathrm{SE}$ & $\mathrm{n}$ \\
\hline Hydroxybutyrate & $100 \pm 2$ & 9 & 4 & 7 & $2.1 \pm 0.2$ & 5 & $1.0 \pm 0.1$ & 5 \\
\hline$D$-Lactate & $99 \pm 2$ & 9 & 6 & 9 & $2.2 \pm 0.2$ & 9 & $0.6 \pm 0.05$ & 9 \\
\hline Lactose & $101 \pm 3$ & 9 & 5 & 17 & $2.4 \pm 0.3$ & 17 & $0.7 \pm 0.08$ & 17 \\
\hline
\end{tabular}

1 The lowest concentration in (a) the undeproteinized sample and (b) the luminometer reaction well, that was significantly different from the mean blank (at $99 \%$ confidence).

Tab. 3 Concentration of reagent components that result in a slight $(10 \%)$ or large $(50 \%)$ inhibition of the light response to 500 $\mathrm{nmol} / \mathrm{l} \mathrm{NADH}$.

\begin{tabular}{lcc}
\hline & \multicolumn{2}{c}{ Concentration $(\mathrm{mmol} /)^{\mathrm{a}}$} \\
\cline { 2 - 3 } & $10 \%$ inhibition $^{\mathrm{b}}$ & $50 \%$ inhibition $^{\mathrm{b}}$ \\
\hline Ascorbic acid & 0.07 & 0.37 \\
Hydrazine sulphate & $>0.07$ & \\
Perchlorate ions & $>8.0$ & $>150$ \\
Phosphate $^{\mathrm{c}}$ & 95 & 20 \\
Sodium hydroxide $^{\mathrm{T}}$ & $<2$ & 8.0 \\
\hline
\end{tabular}

a The final concentration in the luminometer reaction well (i.e. in a final volume of $60 \mu \mathrm{l}$ ).

b The light response in the absence of the reagent component was taken as $100 \%$.

c The light response at the concentration normally present in the diluted reagent (i.e. in a final volume of $60 \mu \mathrm{l}$ ) was taken as $100 \%$.

nescent assay, and may be applied to a range of metabolite assays which result in NADH production, with little modification of these existing assays. In addition, the assays were developed for micro-samples of plasma from the piglet (an accessible and cost-effective medical model). The small volume of plasma required means

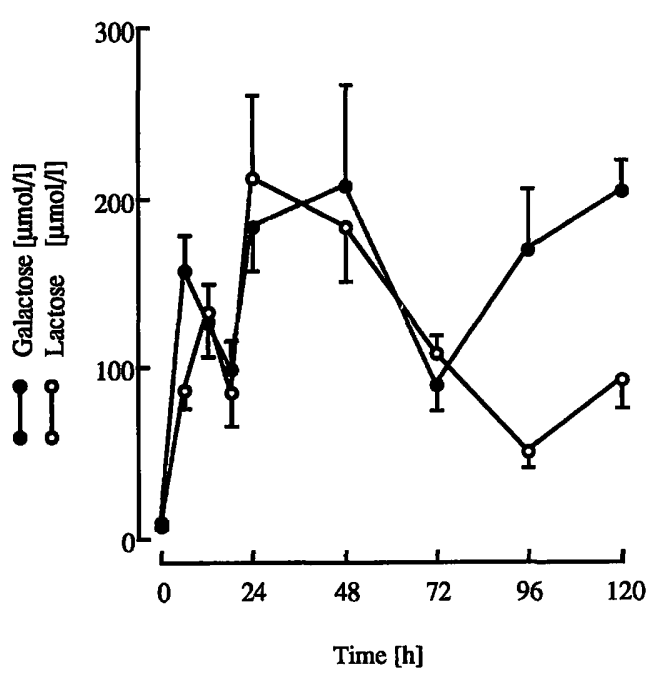

Fig. 3 Concentration of galactose and lactose in the plasma of suckling piglets over the first 120 hours after birth $\left(t_{0}\right)$. All values given are mean $\pm \mathrm{SE}(\mathrm{n}=11)$. that less invasive blood sampling techniques may be used, such as finger, ear or heel pricks.

The ML2250 Microlite Luminometer reads each well in a 96-well plate in approximately 19 minutes, which is considerably faster than previously described methods $(1,3)$. The opaque Microlite ${ }^{\circledR}$ plates used for the bioluminescent reaction maximized sensitivity and eliminated cross talk. However, in preliminary experiments it was found that the initial reactions involving the conversion of the metabolite and the co-production of NADH, did not complete in the Microlite ${ }^{\circledR}$ plates. Therefore the initial reaction(s) was carried out in 96-well V-bottomed plates. The separation of the metabolite-specific reaction(s) from the bioluminescent reaction, allowed a greater dilution of the sample and reagent, thus decreasing possible interference or inhibition of the bioluminescent reactions.

Although sodium hydroxide caused some inhibition of the light response (tab. 3) the use of sodium hydroxide as a diluent served several purposes. Addition of the sodium hydroxide to the metabolite-specific reaction made the conditions sufficiently alkaline to stop enzymatic reactions at a designated time point, thus limiting

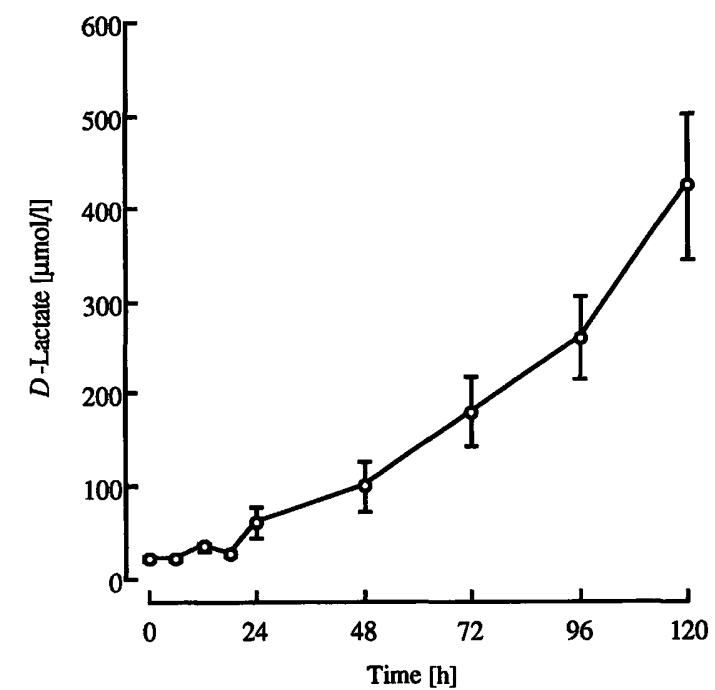

Fig. 4 Concentration of $D$-lactate in the plasma over the first 120 hours after birth $\left(t_{0}\right)$ in suckling piglets. All values given are mean $\pm \mathrm{SE}(\mathrm{n}=11)$. 
the contribution of any contaminating enzymes (3). Furthermore, NADH is unstable at high dilution, but stability can be increased if the NADH in the reaction mixture is in alkaline conditions (12). Ascorbic acid at a concentration of $2 \mathrm{mmol} / \mathrm{l}$ or greater, also stabilizes NADH (12) and was therefore included in the longer initial incubation for $D$-lactate. However, the final concentration of ascorbic acid in the luminometer well was kept to a minimum to prevent inhibition of the light response.

Evaluation of the methods showed that the precision was satisfactory and that the recoveries were quantitative. There was some interference of the kinetic reaction (i.e. the bioluminescent reactions) by various components of the assay mixtures, however, these were minimized with increased dilution before transfer to the Microlite ${ }^{\circledR}$ plates. Furthermore, inhibition was standard for the plate and did not involve sample to sample variation. In early experiments, which were run at room temperature, there was a significant change in the kinetic response of the bioluminescent reagent over the plate due to temperature variations. However, the reaction plate could be maintained at a constant $\left( \pm 2{ }^{\circ} \mathrm{C}\right)$ temperature between $30^{\circ} \mathrm{C}$ and $40^{\circ} \mathrm{C}$, which was sufficient to keep the variability over a plate at acceptable $(<5 \%)$ levels.

The bioluminescent assay was coupled to three assays with possible clinical applications. Measurement of plasma lactose showed that despite a continuing increase in the concentration of lactose in the milk of the sow over the first 5 days post-partum (13-14), and the high concentration of galactose in the plasma of the piglets, there was a decline in the concentration of lactose in the piglet plasma, after 24 hours. This agrees with previous reports indicating that 'closure' of the gut of the piglet to macromolecular uptake occurs at approximately 24 to 36 hours after birth (13-14). Thus, this assay may have clinical applications for the investigation of gut permeability/damage. Furthermore, this assay could be adapted for the determination of lactulose $(17-19)$, which would remove variation due to differences in the hydrolytic capacity between individuals.

$\beta$-Hydroxybutyrate is the major ketone body circulating in the blood of healthy individuals (19). During ketosis the concentration, as well as the proportion of $\beta$-hydro- xybutyrate increases (20), although the extent of the increase is variable. The traditional diagnostic spot test detects acetoacetate and acetone, but does not react with $\beta$-hydroxybutyrate. Thus, ketosis may be greatly, and variably, under-estimated. Several methods have been described for the kinetic measurement of $\beta$-hydroxybutyrate, however, these methods differ considerably with regards to reaction conditions, and interference from unidentified causes could invalidate these methods (21). Coupled to the bioluminescent reaction, the assay described here provides an easy, cost effective means for the identification and investigation of clinical and subclinical ketosis in humans and animals, using only small samples of plasma.

Acidosis due to $D$-lactate is well known in ruminants after carbohydrate over-feeding (22), and has been described in man (23). The presence of $D$-lactate in body fluids indicates either bacterial invasion or absorption from an area of high bacterial activity, such as the gut (24). In the present study, the timing of the increase in the concentration of plasma $D$-lactate agreed with previous reports indicating colonization of the sterile gut of the newborn piglet (25). Changes in plasma $D$-lactate can also be used to indicate the success of dietary management of $D$-lactic acidosis in short bowel syndrome (26). The assay for $D$-lactate described in this paper, provides a sensitive and specific means for monitoring $D$-lactate acidosis.

The present bioluminometric method affords several advantages over earlier methods for metabolite determination in plasma samples. An important improvement is the increased stability of the bioluminescent reagent, which may be stored frozen for several months. Furthermore, the large dilution of sample prior to reaction with the bioluminescent reagent has completely removed sample-inhibition of the luminescence signal, which has remained a problem with modern luminometric techniques (2).

\section{Acknowledgements}

The authors would like to acknowledge the assistance of Miss Christine Wakeford, Wandalup Farms for the use of their facilities and animals, and the financial support of the Pig Research and Development Corporation of Australia.

\section{References}

1. Arthur PG, Kent J, Hartmann PE. Microanalysis of the metabolic intermediates of lactose synthesis in human milk and plasma using bioluminescent methods. Anal Biochem 1989; 176:449-56.

2. Jüngling $E$, Timmerman $M$, Aretz $A$, Ionescu I, Mertens $M$, Löken $C$, et al. Luminometric measurement of subnanomole amounts of key metabolites in extracts from isolated heart muscle cells. Anal Biochem 1996; 239:41-6.

3. Arthur PG, Hochachka PW. Automated analysis of cellular metabolites at nanomolar to micromolar concentrations using bioluminescent methods. Anal Biochem 1995; 227:281-4.

4. Agren A, Berne C, Brolin SE. Photokinetic assay of pyruvate in the islets of Langerhans using bacterial luciferase. Anal Biochem 1977; 78:229-34.

5. Stanley PE. Determination of subpicomole levels of NADH and FMN using bacterial luciferase and the liquid scintillation spectrometer. Anal Biochem 1971; 39:441-53.

6. Gryboski JD, Thayer WR (jr), Gabrielson IW, Spiro HM. Disacchariduria in gastrointestinal disease. Gastroenterology 1963; 45:633-7.

7. Kientsch-Engel RI, Siess EA. D-(-)-3-Hydroxybutyrate and acetoacetate. In: Bergmeyer HU, Bergmeyer J, Graßl M, edi- 
tors. Methods of enzymatic analysis. Weinheim: Verlag Chemie, 1986: 8:60-9.

8. Krebs HA, Mellanby J, Williamson DH. The equilibrium constant of the $\beta$-hydroxybutyrate dehydrogenase system. Biochem J 1962; 82:96-8.

9. Bergmeyer HU, Gawehn K, Klotzsch H. Purification and properties of crystalline 3-hydroxybutyrate dehydrogenase from Rhodopseudomonas spheroides. Biochem J 1967; 102:42331.

10. McLellan AC, Phillips SA, Thornalley PJ. Fluorometric assay of D-lactate. Anal Biochem 1992; 206:12-6.

11. Holmes MA, Arthur PG, Hartmann PE. Changes in the concentrations of glucose and galactose in the peripheral blood of suckling pigs. J Dairy Res 1990; 57:331-7.

12. Passonneau JV, Lowry OH. Enzymatic analysis. A practical guide. Totowa, New Jersey: Humana Press, 1993.

13. Klobasa F, Werhahn E, Butler JE. Composition of sow milk during lactation. J Anim Sci 1987; 64:1458-66.

14. Kent JC, Arthur PG, Hartmann PE. Citrate, calcium, phosphate and magnesium in sow's milk at initiation of lactation. J Dairy Res 1998; 65:In press.

15. Lecce, JG. Effect of dietary regime on cessation of uptake by piglet intestinal epithelium (closure) and transport to the blood. J Nutr 1973; 103:751-6.

16. Clarke RM, Hardy RN. Histological changes in the small intestine of the young pig and their relationship to macromolecular uptake. J Anat 1971; 108:63-77.

17. Behrens RH, Docherty H, Elia M, Neale G. A simple enzymatic method for the assay of urinary lactulose. Clin Chim Acta $1984 ; 137: 361-7$.

18. Northrop CA, Lunn PG, Behrens RH. Automated enzymatic assays for the determination of intestinal permeability probes in urine. 1. Lactulose and lactose. Clin Chim Acta 1990; 187:79-88.
19. Wildenhoff KE. Diurnal variation in the concentrations of blood acetoacetate, 3-hydroxybutyrate and glucose in normal persons. Acta Med Scand 1972; 191:303-9.

20. Stephens JM, Sulway MJ, Watkins JP. Relationship of blood acetoacetate and 3-hydroxybutyrate in diabetes. Diabetes $1971 ; 20: 485-9$.

21. Li PK, Lee JT, MacGillvray MH, Schaefer PA, Siegel JH. Direct fixed time kinetic assays for $\beta$-hydroxybutyrate and acetoacetate with a centrifugal analyzer or a computer-backed spectrophotometer. Clin Chem 1980; 26:1713-7.

22. Dunlop RH, Hammond PB. D-Lactic acidosis of ruminants. Ann NY Acad Sci 1964; 119:1109-30.

23. Oh MS, Phelps KR, Traube M, Barbosa-Saldivar JL, Boxhill C, Carroll HJ. D-Lactic acidosis in a man with the short-bowel syndrome. New Engl J Med 1979; 394:294-52.

24. Smith SM, Eng RHK, Buccini F. D-Lactic acid measurements in the diagnosis of bacterial infections. J Infectious Dis 1986; 165:658-64.

25. Wilbur RD, Catron V, Quinn LY, Speer VC, Hays VW. The intestinal flora of the pig as influenced by diet and age. J Nutr $1970 ; 71: 168-75$.

26. Mayne AJ, Handy DJ, Preece MA, George RH, Rooth IW. Dietary management of D-lactic acidosis in short bowel syndrome. Arch Dis Childhood 1990; 65:229-31.

\section{Received June 30/September 12, 1997}

Corresponding author: M. J. Thompson, Centre for Mediterranean Agricultural Research, CSIRO, Private Bag, PO Wembley W. A. 6014, Australia

Tel.: +61 (0)8 93336670 , Fax: +61 (0)893878991, e-mail: m.thompson@ccmar.csiro.au 